\title{
Theoretical Issues in Mathematics Education: An Introduction to the Presentations
}

\author{
Angelika Bikner-Ahsbahs and David Clarke
}

\section{Report}

In the last decade, the issue of theories has been raised more than once in international conferences on mathematics education (e.g. PME 2005, 2010; CERME since 2005; ICME 11). Since 2006, a European group for the networking of theories has researched the question how mathematics education can deal with different theories (Bikner-Ahsbahs et al. 2010). All these events have shown the diversity of theories to be inherent in mathematics education. TSG 37 of ICME 12 has gathered an up-to date version of the state of the reflection on theories with respect to the theoretical questions and underpinnings of the international field, at the same time stimulating insightful exchanges and discussions crossing theoretical cultures within mathematics education. Group discussions addressed the following issues: What theories do we need in mathematics education? What do they have to cover according to the conditions, roles and functions of theory use and development, and how can we deal with the diversity of theories in a scientific fruitful way?

Radford (2008) provided a meta-theoretical frame for theories. Referring to Lotman (1990), Radford characterized the space of theory cultures as a semiosphere: a dynamically evolving space. According to Radford, theory is a dynamic way of understanding, provided and performed on the basis of a triplet $(\mathrm{P}, \mathrm{M}, \mathrm{Q})$ :

Organizers Co-chairs: Angelika Bikner-Ahsbahs (Germany), David Clarke (Australia); Team Members: Cristina Sabena (Italy), Minoru Ohtani, (Japan), Gelsa Knijnik (Brazil), Jin Young Nam (Korea).
A. Bikner-Ahsbahs $(\square)$
University of Bremen, Bremen, Germany
e-mail: bikner@math.uni-bremen.de
D. Clarke
University of Melbourne, Melbourne, Australia
e-mail: d.clarke@unimelb.edu.au 
the set $\mathrm{P}$ of principles of the theoretical culture, the set $\mathrm{M}$ of methodologies that refer to $\mathrm{P}$ including methods and the set $\mathrm{Q}$ of paradigmatic questions in the core of the theory, its $\mathrm{P}$ and $\mathrm{M}$. The developmental dynamic is constituted by research and the exchange of research results $\mathrm{R}$ referring back to the triplet $(\mathrm{P}, \mathrm{M}, \mathrm{Q})$ (Radford 2012). This understanding of the terms theory and semiosphere provides a framework for understanding the connection of theories as exchanges and dialogues between their parts. Connections can be created among the theories parts $[(\mathrm{P}, \mathrm{M}$, $\mathrm{Q}), \mathrm{R}$ ] and structured according to their degree of integration in the landscape of networking strategies: understanding and making understandable, comparing and contrasting, combining and coordinating, and locally integrating and synthesizing (Bikner-Ahsbahs and Prediger 2010). The first two pairs can always be done but the third and the fourth pair can only be executed if the principles of the theories are close enough. TSG 37 offered an introduction about the networking of theories, eight long presentations, five short presentations and short statements about the posters within four sessions. The first session involved questions concerning how theories from outside mathematics education might fruitfully inform the dynamics of research within mathematics education; in particular, it addressed the challenge of identifying theories suitable for use in mathematics education, contrasting the treatment of particular constructs relevant to mathematics education within two or more theories, suggesting inadequacies in the capacity of currently available theories to meet the needs of mathematics education, and recommending what developments are required. It was established early in the discussion that no single theory can claim to be comprehensive and so all theories are consequently partial and selective in their focus and the phenomena they describe and attempt to explain (Clarke 2011). Two presentations were discussed. Knijnik positions culture at the heart of teaching and learning mathematics and addresses the issue of Ethnomathematics as an offer to think of cultural differences in grammar and logic. Her approach can be regarded as a coordination of two background theories rooted in the work of Wittgenstein and his language games and of Foucault and his work on how discourse establishes truth in the culture. Pais and Valero point to the demand of mathematics education for all and recommend the inclusion of economic considerations in the theories employed in mathematics education. According to Pais and Valero, current theories do not accommodate these concerns. The two contributions offer different perspectives: according to Pais and Valero, we have to be more open in the direction of political and economic value of mathematics, and, according to Knijnik, we must see philosophies of teaching and learning as parts of the distinct cultures from which they have developed and in which they are applied.

The second session investigated the role and function of theories in mathematics education (and mathematics education research), their capacity to provide insight into one or more different contexts or issues in mathematics education, and the methodological entailments of selecting particular theories in the process of research and design. Drawing on Vygoskian theory, Albert positioned learning mathematics as a cultural-historical activity mediated by a sign system and applied this to serve teaching practice by the use of algebra tiles. Hatfield asked how a theory could be built to capture lived mathematical experience in order to 
investigate this phenomenon. He included two views, the phenomenological and the constructivist view, to start building a theory. Trninic and Kim adopt a radical position on embodied cognition. They regard learning mathematics to be cognitively embodied and employ this in the design of computer-based environments. To do so, theory and design have to co-inscribe, e.g. they mutually inform and entail each other. These three presentations accorded theory different roles and functions: (1) theory as a source of models to be applied to the practice of teaching and learning, (2) theory constructed to understand a specific phenomenon, and (3) theory as informing instruction to be co-developed with design towards a specific goal. The researcher's perspective on learning mathematics and on the aim and function of research determines what kind of theory is considered suitable. Hatfield grappled with the new idea of lived mathematical experience within learning suggesting that this focus has to be intensively theorized before it brings a theory to the fore. Trninic and Kim reconceptualised embodied cognition by situating it in design experiments and by looking at the theory in a new way. Albert used research results from a background theory with a long tradition (Vygotski's social psychology) employed in mathematics education to inform practice.

Session three discussed the question of how to deal with different theories in a scientific way, addressing the challenge of utilising the results of research studies in mathematics education undertaken using different theories. The generic term "networking" was employed to include strategies such as connecting, comparing, contrasting, combining, coordinating, integrating, and synthesising. Such strategies are intended to provide heightened insight into a complex setting. The session involved reporting examples of the networking of theories, their limits and their potential for advancing mathematics education. Three presentations addressed these issues. Even investigated the same data set from two philosophical traditions: constructivist theory, investigating learning by looking at cognitive development; and activity theory, used to investigate the teacher's participation. She showed that the object of investigation and the research questions were different according to the particular theory and therefore the results of the analysis and the answers to the research questions were also different, but complementary and mutually informative. She inferred from this that the use of more than one theory demands parallel lines of research and meta-theoretical exchanges. Trigueros et al. undertook a theoretical study to investigate the different meanings of mathematical object in Action-process-object-schema (APOS) theory and in the onto-semiotic approach. She showed that some concepts within one theory could be interpreted by the other, suggesting that these concepts could be associated with measures or results amenable to comparison, that is, they were commensurable, whereas results associated with other concepts might be incommensurable but compatible because they were not mutually contradictory; but could be seen as disjoint or complementary. The relationship between different theories cannot be simplistically categorised as either commensurable/incommensurable or as compatible/incompatible. Theories may partly overlap and may be mutually informative to some extent. The issue of limits was raised by the third presentation from Kidron and Monaghan, which discussed the complexity of dialogue between theories. In this presentation, Kidron showed 
that dialogues as exchanges between theoretical cultures can be regarded on two levels: (i) the cultural level of theories participant in research processes-a possible mechanism to network theories; but also (ii) the individual level, where researchers work with different theories within one project and must forge connections between theories in the process of constructing their findings. Both data and results are constructed within research through methodologies that reflect the choice of theories. In this way, the networking (combination or juxtaposition) of theories might lead to uncover blind spots in the making of data and in the analyses, clarify the theories' boundaries but also advance research through enriching results.

The use of multiple theories (and associated parallel analyses) in a single research project can serve several purposes (Clarke 2011):

- By addressing different facets of the setting/s and providing a richer, more complex, more multi-perspectival portrayal of actors and actions, situations and settings;

- By offering differently-predicated explanations and differently-situated propositions;

- By increasing the authority of claims (and instructional advocacy), where findings (both explanations and emergent propositions) were coincident across analyses;

- By qualifying the nature of claims, where findings of the parallel analyses were inconsistent or contradictory (cf. Even's analyses of "the same data");

- By providing a critical perspective on the capacity of each particular theory to accommodate and/or explain data related to the same events in the same setting.

In session four, the evolving discourse could be used to discuss short presentations, reporting studies with multiple theoretical perspectives on mathematical imagination (Aralas), on mathematical visuality (Flores), and on concept formation (Rembowski). Rosa and Aparecida addressed philosophical considerations regarding mathematical technology and Kusznirczuk suggested according theories the status of organising principles for coordinating the objects that populate our discourses and our methods.

In summary: Since research questions are intimately connected with the theoretical frameworks in which they are elaborated, it may appear problematic to use different theories to answer the same research question. However, different theories may usefully address different questions about the same setting (e.g. the mathematics classroom) or even the same issue (e.g. the instructional use of representations). Researchers should draw on the expertise of the various theoretical cultures to enrich the general discourse of the mathematics education community and respond to society's major questions at an appropriate level of complexity. The discussion raised the question up to what point researchers might be able to consciously choose a theory or a theoretical paradigm for their research and it brought to the fore the criteria under which theories might be evaluated: the dichotomy true/ wrong was contrasted with the useful/useless one, and the concepts of validity and viability were considered. The work carried out in this TSG has constituted a small but solid step in fighting back this danger for mathematics education. 
Open Access This chapter is distributed under the terms of the Creative Commons Attribution Noncommercial License, which permits any noncommercial use, distribution, and reproduction in any medium, provided the original author(s) and source are credited.

\section{References}

Bikner-Ahsbahs, A., \& Prediger, S. (2010). Networking of Theories-An Approach for Exploiting the Diversity of Theoretical Approaches. In B. Sriraman \& L. English (Eds.), Theories of mathematics education: seeking new frontiers (pp. 479-512). New York: Springer, Advances in Mathematics Education series, Vol. 1.

Bikner-Ahsbahs, A., Dreyfus, T., Kidron, I., Arzarello, F., Radford, L., Artigue, M., \& Sabena, C. (2010). Networking of theories in mathematics education. In M. M. Pinto, \& T. F. Kawasaki (Eds.), Proc. $34^{\text {th }}$ Conf. of the Int. Group for the Psychology of Mathematics Education, vol. 1 (pp. 145-175). Belo Horizonte, Brazil: PME.

Clarke, D. J. (2011). A Less Partial Vision: Theoretical Inclusivity and Critical Synthesis in Mathematics Classroom Research. In J. Clark, B. Kissane, J. Mousley, T. Spencer \& S. Thornton (Eds.) Mathematics: Traditions and [New] Practices. Proceedings of the 2011 AAMT-MERGA conference (pp. 192-200). Adelaide: AAMT/MERGA.

Lotman, Y. (1990). Universe of the mind. A semiotic theory of culture. London: I. B. Taurus.

Radford, L. (2008). Connecting theories in mathematics education: Challenges and possibilities. ZDM Mathematics Education, 40, 317-327.

Radford, L. (2012). On the growth and transformation of mathematics education theories. Paper presented at the International Colloquium: The Didactics of Mathematics: Approaches and Issues. A homage to Michèle Artigue. http://www.laurentian.ca/educ/lradford. Accessed 29 October 2013. 